\title{
A explicitação na tradução inglesa de termos culturalmente marcados da obra $O$ povo brasileiro: a formação e o sentido do Brasil de Darcy Ribeiro
}

Talita Serpa e Diva Cardoso de Camargo*

\section{Introdução}

A pesquisa antropológica no Brasil teve início com estudos de pesquisadores estrangeiros como o funcionalista Radcliffe-Brown e o estruturalista Lévy-Strauss, os quais fizeram das povoações indígenas brasileiras objetos de suas análises. Contudo, na contramão das perspectivas analíticas europeias, Darcy Ribeiro propôs a elaboração de uma avaliação das condições do processo civilizatório nacional, livre da ação teórica precedente, criando assim uma série de seis livros intitulada Antropologia da Civilização.

O autor promoveu novos parâmetros para observação da sociedade enquanto objeto, criou novos termos e reviu categorizações de hipóteses precedentes, adaptando-as à proposta de uma Antropologia Brasileira, feita por pesquisadores brasileiros imersos no contexto social de origem.

Sendo assim, a pesquisa no Brasil passou a valorar as ordenações político-sociais nacionais e a tradução na direção português $\rightarrow$ inglês constituiu-se como necessária para ampliar o alcance da difusão dos conhecimentos apresentados por Ribeiro, de modo a colocar os antropólogos brasileiros entre os principais autores das Ciências Sociais no mundo.

\footnotetext{
* Talita Serpa é Doutoranda pelo Programa de Pós-Graduação em Estudos Linguísticos da Universidade Estadual Paulista- UNESP. Diva Cardoso de Camargo, Doutora em Tradução pela Universidade de São Paulo, é Professora Adjunta da UNESP.
} 
SERPA e CARDOSO DE CAMARGO, A explicitação na tradução inglesa de termos culturalmente marcados da obra O povo brasileiro: a formação e o sentido do Brasil de Darcy Ribeiro.

Neste trabalho, analisamos alguns traços tradutórios identificados como explicitação no cotexto de brasileirismos terminológicos, contidos na obra de Darcy Ribeiro: O povo brasileiro: A formação e o sentido do Brasil (1995) e na respectiva tradução The Brazilian People: formation and meaning of Brazil (2000), realizada por Gregory Rabassa.

Este tipo de investigação salienta a relevância de pesquisas voltadas para os Estudos da Tradução Baseados em Corpus (BAKER, 1993, 1995, 1996; CAMARGO, 2005, 2007) e para a Linguística de Corpus (BERBER SARDINHA, 2000, 2004), mostrando a observação teórica por meio de exemplos de uso real da língua.

\section{Fundamentação Teórica}

\subsection{Estudos da Tradução Baseados em Corpus e a Linguística de Corpus}

A partir da evolução das pesquisas interdisciplinares em Tradução, a pesquisadora Mona Baker (1993, 1996, 1999, 2000) propôs uma nova leitura teórico-metodológica que assumiu posição de destaque no meio acadêmico. Para a autora:

[Os] textos traduzidos registram eventos comunicativos genuínos e como tais não são nem inferiores nem superiores a outros eventos comunicativos em qualquer língua. Entretanto, eles são diferentes, e a natureza dessa diferença precisa ser explorada e registrada. ${ }^{1}$ (BAKER, 1993, p.234).

Para promover seu ponto de vista analítico para os Estudos da Tradução Baseados em Corpus, a teórica desenvolveu a proposta de um quadro epistemológico capaz de abarcar os principais elementos constituintes do processo tradutório em uma análise reflexiva relevante. Compreendeu a apreciação do Texto Meta (TM) em seu ambiente de interação e deu abertura para um enfoque comparativo em corpora eletrônicos. Ao contrário de outros teóricos que procuravam ressaltar valores culturais ou puramente

\footnotetext{
${ }^{1}$ Translated texts record genuine communicative events and as such are neither inferior nor superior to other communicative events in any language. They are however different, and the nature of this difference needs to be explored and recorded.
} 
SERPA e CARDOSO DE CAMARGO, A explicitação na tradução inglesa de termos culturalmente marcados da obra O povo brasileiro: a formação e o sentido do Brasil de Darcy Ribeiro.

linguísticos, esta autora buscou elucidar a natureza do TM e do processo tradutório, ou seja, delimitar o objeto e o método de uma investigação científica independente.

Com isso, Baker (1995) deu início a pesquisas com corpora, as quais, de modo geral, fundamentavam-se por meio do uso de computador. Seus princípios corroboraram a elaboração de análises que consideram um corpus como:

\begin{abstract}
Um conjunto de dados linguísticos (pertencentes ao uso oral ou escrito da língua, ou a ambos), sistematizados segundo determinados critérios, suficientemente extensos em amplitude e profundidade, de maneira que sejam representativos da totalidade do uso linguístico ou de algum de seus âmbitos, dispostos de tal modo que possam ser processados por computador, com a finalidade de propiciar resultados vários e úteis para a descrição e análise. (SÁNCHEZ, 1995, p.8-9; traduzido por Berber Sardinha, 2004, p.18).
\end{abstract}

Dessa forma, a Linguística de Corpus ganhou caráter transdisciplinar, sendo utilizada na análise de amplos conjuntos de informação. Considera as investigações de âmbito empírico e verifica a linguagem como um sistema de repetição de padrões e probabilidades.

Para Berber Sardinha (2004), essa “[...] visão da linguagem como sistema probabilístico pressupõe que, embora muitos traços linguísticos sejam possíveis teoricamente, não ocorrem com a mesma frequência" (BERBER SARDINHA, 2004, p.30). De acordo com a abordagem do autor, esses traços não apresentam uma frequência aleatória, pelo contrário, a recorrência de seu uso é regular e pode ser delimitada de acordo com os padrões de repetição em contextos pré-estabelecidos. Nesse sentido, o teórico esclarece que "dizer que a variação não é aleatória, na verdade, é afirmar que a linguagem é padronizada" (BERBER SARDINHA, 2004, p.31).

\title{
2.2. Traços de Explicitação
}

Baker retoma o quadro teórico da Linguística de Corpus para promover as verificações de processos tradutórios reincidentes, aos quais denomina traços. A autora $(1995,1996,2007)$ identifica quatro características resultantes 
SERPA e CARDOSO DE CAMARGO, A explicitação na tradução inglesa de termos culturalmente marcados da obra O povo brasileiro: a formação e o sentido do Brasil de Darcy Ribeiro.

da interferência de sistemas linguísticos específicos, os quais se apresentam tipicamente nos TMs, mas não nos TFs. Entre essas recorrências é possível verificar: a explicitação a simplificação, a normalização e a estabilização. Entre estes, avaliaremos o primeiro:

Explicitação: tendência geral em explicar e expandir dados do TF, por meio de uma linguagem mais explícita, mais clara para o leitor do TM. Manifestações dessa tendência podem ser expressas sintática ou lexicalmente, e podem ser observadas habitualmente, em relação aos TFs, como a maior extensão dos TMs, o emprego exagerado de vocábulos e de conjunções coordenativas explicativas. (CAMARGO, 2007, p. 31).

É importante salientar que não existe uma fronteira exata entre os traços, dado que em alguns momentos eles podem sobrepor-se. A simplificação, por exemplo, pode indicar que o tradutor estaria buscando tornar o TM mais simples para o leitor da cultura de chegada; esses traços também poderiam mostrar que o tradutor procurou adequar o TM às estruturas da língua de chegada.

\subsection{Os Estudos da Tradução Baseados em Corpus e a Terminologia}

Embora se dediquem a objetivos distintos, a Tradução e a Terminologia complementam-se em se tratando da tradução técnica e especializada. Tal fato é destacado por Aubert (1996) que salienta:

(...) se, na sua epistemologia e no seu objetivo de estudos, a Terminologia e a Tradução abarcam e se conduzem por caminhos distintos, no fazer tradutório e no fazer terminológico esses mesmos caminhos se cruzam e se entrecruzam. Com efeito, como afirma Galinski (1985), translators are probably the largest identifiable individual user group for terminologies...Ou seja, os tradutores profissionais apresentam-se como um dos principais grupos de usuários finais da pesquisa terminológica (glossários, dicionários técnicos, bases de dados terminológicos, etc). (AUBERT, 1996, p. 13-14). 
SERPA e CARDOSO DE CAMARGO, A explicitação na tradução inglesa de termos culturalmente marcados da obra O povo brasileiro: a formação e o sentido do Brasil de Darcy Ribeiro.

Observamos que o estudo terminológico é uma atividade que procura compilar e apresentar os termos de um dado campo a fim de que seu uso torne-se parte do comportamento comum aos seus especialistas. Com a tecnologia e com o desenvolvimento das relações de comércio entre os países do mundo todo, a tradução técnica e especializada vem sendo cada vez mais requisitada e o tradutor necessita estar apto a desempenhar sua tarefa com rapidez, eficiência e perfeição.

Devemos acrescentar também que, no âmbito de nossa pesquisa, consideramos como termo a "designação, por meio de uma unidade linguística, de um conceito definido em uma língua de especialidade" (ISO 1087, 1990, p. 5, apud BARROS, 2004, p. 40). Assim, a Terminologia tem um papel importante, dado que fornece a base teórica para a identificação de termos das Ciências Sociais que nos propusemos a analisar.

\subsection{Brasileirismos Terminológicos: A tradução nas Ciências Sociais}

No que concerne à linguagem de especialidade das Ciências Sociais projetada por Darcy Ribeiro, é importante conhecer os padrões próprios da natureza da produção teórica do autor a fim de elaborar novos textos antropológicos, assim como de traduzir suas proposições e questionamentos, levando ao conhecimento do mundo o papel que este autor atribui às nações latino-americanas.

Notamos que, no âmbito das Ciências Sociais, como aponta Winick (1961), os antropólogos são chamados, ao longo de suas pesquisas, a criar termos especiais. Muitos desses termos não podem ser definidos com absoluta precisão e são usados com base em um tácito consenso sobre seus significados. Este acordo depende mais de uma noção compartilhada de um termo do que do claro veredicto sobre a denotação da palavra em si.

No âmbito dos trabalhos antropológicos realizados no Brasil, os termos e conceitos assumem o caráter de brasileirismos terminológicos, os quais, segundo Faulstich (2004), constituem-se enquanto unidades lexicais com caráter funcional em contextos científicos específicos. A teórica defineos como "palavras, locuções e outra estrutura sintagmática criada e formada no Brasil, que tenha significado autônomo e esteja encerrada num con- 
SERPA e CARDOSO DE CAMARGO, A explicitação na tradução inglesa de termos culturalmente marcados da obra O povo brasileiro: a formação e o sentido do Brasil de Darcy Ribeiro.

ceito de especialidade, que possibilite reconhecer a área a que pertente" (FAULSTICH, 2004).

Costa (2006) aponta que a categoria de brasileirismos é atestada pelo Novo Dicionário Aurélio, no qual, entre as vinte e seis mil entradas consideradas como culturalmente marcadas, mil são determinadas como exemplos terminológicos, estando englobadas por campos como: capoeira, música, folclore, economia, política, medicina, etc. Sendo assim, são exemplos dessa terminologia palavras como: "boi", "cabeçada", "ciúme", "descer" e "madrinha".

Assim, é importante para o tradutor que se depare com um texto científico a ser traduzido esteja familiarizado com esse tipo de terminologia adequada a cada subárea das Ciências Sociais. Dessa forma, tanto pesquisadores da área quanto os estudantes de Tradução estariam diretamente beneficiados com os resultados de trabalhos voltados para esses propósitos.

\section{Material e Método}

Para esta investigação, foram compilados os seguintes corpora: um corpus de estudo paralelo constituído pela obra $O$ povo brasileiro: formação e sentido do Brasil, de autoria de Darcy Ribeiro, publicada originalmente em português no ano de 1995 (total de itens: 115.474), e a respectiva tradução para o inglês, realizada por Gregory Rabassa, sob o título The Brazilian People: formation and meaning of Brazil, publicada em 2000 (total de itens: 139.858).

Também utilizamos dois corpora de referência para a extração de palavras-chave ${ }^{2}$. Em português, utilizamos o corpus Lácio-Ref, um corpus aberto e de referência do português contemporâneo do Projeto Lácio-Web, composto de textos em português brasileiro, tendo como característica serem escritos respeitando a norma culta. A taxonomia de gêneros do LácioRef é composta por textos científicos, de referência, informativos, jurídicos, prosa, poesia, drama, instrucionais e técnico-administrativos (ALUíSIO et. al., 2003).

\footnotetext{
2 Em Linguística de Corpus, "palavras-chave" são aquelas cuja frequência no corpus de estudo é estatisticamente significante se comparada à frequência da mesma palavra em um corpus de referência (corpus de língua geral pelo menos cinco vezes maior que o corpus de estudo).
} 
SERPA e CARDOSO DE CAMARGO, A explicitação na tradução inglesa de termos culturalmente marcados da obra O povo brasileiro: a formação e o sentido do Brasil de Darcy Ribeiro.

Para a extração de palavras-chave em inglês, empregamos o corpus de referência British National Corpus (BNC Sampler), composto por textos originalmente escritos em inglês e desenvolvido pela parceria de membros da Oxford University Press, Longman Group Ltd., Chambers Harrap, Oxford University Computing Services, UCREL - Lancaster University e British Library Research and Development Centre.

Para o levantamento dos dados, foram utilizadas as ferramentas KeyWords e WordList do software WordSmith Tools, as quais facilitam a compilação dos termos.

\subsection{Levantamento dos traços de Explicitação}

A identificação dos traços de explicitação pertinentes aos termos culturalmente marcados presentes no corpus de estudo segue as premissas do levantamento realizado no artigo A explicitação como traço de um habitus tradutório para brasileirismos terminológicos em língua inglesa: um estudo baseado no corpus da obra O Povo Brasileiro, de Darcy Ribeiro (SERPA, CAMARGO, 2013). Nesse sentido, no presente trabalho observamos as listas de palavras mais frequentes ${ }^{3}$, bem como as listas de palavras-chave. Utilizamos, para tanto, as ferramentas WordList e Keywords para o subcorpus do TF em relação aos dados das listas extraídas para o subcorpus do TM. Com base nesses conjuntos de informações, passamos à interpretação dos resultados, procurando confirmar o princípio de explicitação.

\section{Análise e Discussão dos Resultados}

Para a análise de traços de explicitação no cotexto da tradução de brasileirismos da obra $O$ povo brasileiro, apresentamos, abaixo, as Tabelas 1 e 2, com as palavras de maior frequência no TF e no TM do corpus de estudo:

\footnotetext{
${ }^{3}$ As listas condizem com os dados apresentados no trabalho já publicado.
} 
SERPA e CARDOSO DE CAMARGO, A explicitação na tradução inglesa de termos culturalmente marcados da obra O povo brasileiro: a formação e o sentido do Brasil de Darcy Ribeiro.

\begin{tabular}{l|l|l|l}
\hline 1. Índios (448) & 4. Social (174) & 7. Brasileiros (156) & 10. Povo (144) \\
2. População (286) & $\begin{array}{l}\text { 5. Sociedade (167) } \\
\text { 8. Gente (152) }\end{array}$ & \\
3. Trabalho (207) & 6. Negros (164) & 9. Produção (145) & \\
\hline
\end{tabular}

TABELA 1: Lista das dez palavras mais frequentes no subcorpus de estudo da obra $O$ povo brasileiro

\begin{tabular}{l|l|l|l}
\hline 1. Indians (468) & 4. Land (265) & 7. Order (199) & 10. Slaves (177) \\
2. People (464) & 5. Population (265) & $\begin{array}{l}\text { 8. Society (187) } \\
\text { 9. Work (178) }\end{array}$ & \\
3. Brazilian (310) & 6. Social (208) & \\
\hline
\end{tabular}

TABELA 2: Lista das dez palavras mais frequentes no subcorpus de estudo da obra The Brazilian People

Observamos que o número de ocorrências de um dado termo pode revelar uma possível tendência do autor em enfatizar determinados conteúdos analíticos sócioantropológicos, de modo que é importante que o tradutor, ao iniciar a atividade de composição do TM, tenha em mente as propostas teóricas do autor e os conceitos que salienta e constrói. Tal trabalho torna-se viável por meio da utilização de corpora.

Ao fazer uso de um conjunto lexical específico com maior ou menor explicitação, tanto o autor quanto o tradutor tendem a direcionar os focos de leitura e compreensão da obra. Assim, ao constituir seu comportamento tradutório, Rabassa explora as questões relacionadas à fundamentação da Antropologia da Civilização, aproximando o TM da proposta inovadora de Darcy Ribeiro.

Verificamos, também, que o tradutor explicita a fim de reorganizar e redesenhar a sociedade brasileira sob o ponto de vista do leitor de língua inglesa. Um bom exemplo dessas ressignificações é encontrado no uso do termo "brasileiro", que ocorre 90 vezes no TF, ao passo que o correspondente em inglês, Brazilian, aparece $310^{4}$ vezes no TM. Considerando as questões gramaticais que podem derivar desse uso, apresentamos, abaixo, a Tabela 3, com a frequência de uso do termo "brasileiro" e de seus derivados na Língua Fonte (LF):

\footnotetext{
${ }^{4}$ Consideramos, aqui, todas as ocorrências, incluindo aquelas em que o termo se associa com outros para compor termos como neo-Brazilian, Afro-Brazilian, proto-Brazilian e Brazilian-ness.
} 
SERPA e CARDOSO DE CAMARGO, A explicitação na tradução inglesa de termos culturalmente marcados da obra O povo brasileiro: a formação e o sentido do Brasil de Darcy Ribeiro.

\begin{tabular}{l|r}
\hline Vocábulos em LF & \multicolumn{2}{|c}{$\begin{array}{c}\text { Frequência de uso dos vocábulos no } \\
\text { subcorpus principal do TF }\end{array}$} \\
\hline Brasileiro & 90 \\
\hline Brasileiros & 156 \\
\hline Brasileira & 156 \\
\hline Brasileiras & 34 \\
\hline
\end{tabular}

TABELA 3: Frequência de uso do vocábulo brasileiro e de seus derivados no subcorpus principal do TF

Com base nas informações fornecidas, observamos regularidade no uso das palavras dentro da obra de Darcy Ribeiro. No entanto, ainda não é possível distinguir entre a base substantival e adjetival dos usos fora de contexto. Por tal razão, apresentamos a Tabela 4 com as subdivisões da função gramatical do conjunto lexical dos vocábulos:

\begin{tabular}{l|r|r}
\hline $\begin{array}{c}\text { Vocábulos em } \\
\text { LF }\end{array}$ & $\begin{array}{c}\text { Frequência de uso como } \\
\text { substantivo }\end{array}$ & $\begin{array}{c}\text { Frequência de uso como } \\
\text { adjetivo }\end{array}$ \\
\hline Brasileiro & 17 & 73 \\
\hline Brasileiros & 104 & 52 \\
\hline Brasileira & 0 & 156 \\
\hline Brasileiras & 0 & 34 \\
\hline
\end{tabular}

TABELA 4: Frequência de uso dos vocábulos como substantivos e como adjetivos no subcorpus principal do TF

Os dados mostram que o autor optou por utilizar com maior frequência o substantivo masculino plural: "brasileiros". Dessa forma, podemos inferir que a definição de "nacionalidade", na $A C$, constitui-se na ideologia de "coletividade" e "agrupamento social".

Vejamos agora, como esse processo se estabelece no TM. Abaixo, apresentamos as Tabelas 5 e 6, com a frequência do vocábulo em inglês e com seu uso nas funções gramáticas de substantivo e adjetivo.

\begin{tabular}{l|cr}
\hline $\begin{array}{c}\text { Vocábulos em Língua Meta } \\
\text { (LM) }\end{array}$ & $\begin{array}{c}\text { Frequência de uso dos vocábulos no } \\
\text { subcorpus principal do TM }\end{array}$ \\
\hline Brazilian & \multicolumn{3}{|c}{} & 310 \\
\hline Brazilians & \multicolumn{2}{|c}{} \\
\hline \multicolumn{2}{|c|}{ TABELA 5: Frequência de uso do vocábulo Brazilian no subcorpus principal do TM }
\end{tabular}


SERPA e CARDOSO DE CAMARGO, A explicitação na tradução inglesa de termos culturalmente marcados da obra O povo brasileiro: a formação e o sentido do Brasil de Darcy Ribeiro.

\begin{tabular}{l|r|rr}
\hline $\begin{array}{c}\text { Vocábulos em } \\
\text { LM }\end{array}$ & \multicolumn{2}{|c|}{$\begin{array}{c}\text { Frequência de uso co- } \\
\text { mo substantivo }\end{array}$} & \multicolumn{2}{|c}{$\begin{array}{c}\text { Frequência de uso como ad- } \\
\text { jetivo }\end{array}$} \\
\hline Brazilian & 15 & 299 \\
\hline Brazilians & 101 & 21 \\
\hline
\end{tabular}

TABELA 6: Frequência de uso dos vocábulos como substantivos e como adjetivos no subcorpus principal do TM

O tradutor interpreta as teorias do autor e passa a tomar o TF como base para produção de seu próprio texto. Em língua inglesa não há distinção entre masculino e feminino para o termo Brazilian o que pode incorrer na generalização da concepção de "nacionalidade", aproximando o público da Cultura Meta ainda mais da proposta de univocidade e coletividade do povo brasileiro.

No âmbito das formas de singular e plural, ao somarmos as ocorrências no TF e no TM, observamos que o número de substantivos em inglês apresenta-se menor após o processo tradutório. Este poderia ser um indício de possível omissão do sentido de "brasileiro" e de sua "brasilidade". No entanto, percebemos que essa supressão de sentido não acontece realmente, pois, no que concerne ao uso dos vocábulos como adjetivos, verificamos que a soma da frequência em LF no singular é de 107 ocorrências. No TM, esse número sobe para 299, isto é, Rabassa pode ter sentido a necessidade de adjetivar mais trechos para deixar clara a procedência de determinadas atividades e hábitos comuns ao Brasil.

Com o auxílio da ferramenta KeyWords, foram geradas as listas de palavras-chave do subcorpus do $\mathrm{TF}$, tomando para contraste o corpus de referência Lácio-Ref. Após esse levantamento, foram também observadas as palavras-chave a partir do TM, tendo como corpus de referência o BNC Sampler. Abaixo, apresentamos as Tabelas 7 e 8 com as respectivas dez palavras-chave de maior índice: 
SERPA e CARDOSO DE CAMARGO, A explicitação na tradução inglesa de termos culturalmente marcados da obra O povo brasileiro: a formação e o sentido do Brasil de Darcy Ribeiro.

\begin{tabular}{l|l|l|l}
\hline 1. Índios & 4. Escravos & 7. Gado & 10. Indígenas \\
2. Terras & 5. Colonial & 8. Povos & \\
3. População & 6. Negros & 9. Civilização & \\
\hline
\end{tabular}

TABELA 7: Lista das dez palavras-chave a partir do subcorpus de estudo da obra $O$ povo brasileiro

\begin{tabular}{l|l|l|l}
\hline 1. Indians & 4. Slaves & 7. Labor & 10. Civilization \\
2. Brazilian & 5. Plantation & 8. Population & \\
3. Brazil & 6. Blacks & 9. Backlands & \\
\hline
\end{tabular}

TABELA 8: Lista das dez palavras-chave a partir do subcorpus de estudo da obra The Brazilian People

Verificamos que embora haja uma possível identificação com o conjunto terminológico do TF em The Brazilian People, não podemos desconsiderar as variações de conceituação presentes nos itens lexicais e a alteração no grau de significação de um termo que essas mudanças de "cenário" podem causar. Analisando alguns dos termos correspondentes das listas de palavras-chave, verificamos que, concernente à constituição da imagem do "índio" (Indian), por exemplo, o Dictionary of Anthropology (1961) remetenos, primeiramente, à questão do vínculo ao território americano e, logo em seguida, à conceituação de um tronco racial mongólico caracterizado pela formação de um grupo de indivíduos de pele escura, face arredondada, cabelos lisos, corpo sem pelos e alguns prognatismos.

O Dicionário de Antropologia: do homem primitivo às sociedades actuais (1983), por sua vez, detalha a constituição de cada grupo indígena já estudado, salientando as principais características de cada um. O verbete iniciase com os "índios da América Latina" (Latin American Indians) e aponta que o continente americano oferece grande variedade humana, que vai desde as tribos indígenas, que em certas regiões da Amazônia ainda hoje se mantêm fora do alcance do homem branco, até os índios que estão integrados à nova sociedade.

A relação que se estabelece na memória do povo brasileiro, ao se evocar o conceito de "índios", vai além da proposta de um grupo racial específico. Na concepção de Darcy Ribeiro, trata-se de um dos núcleos 
SERPA e CARDOSO DE CAMARGO, A explicitação na tradução inglesa de termos culturalmente marcados da obra O povo brasileiro: a formação e o sentido do Brasil de Darcy Ribeiro.

constituintes do coletivo nacional, integrado ao Brasil pela absorção de elementos da mística, da culinária, dos costumes, do vestuário e, em especial, da linguagem.

Observamos que, como estudioso dos elementos culturais presentes no processo tradutório, a reflexão do tradutor sobre o TF de Darcy Ribeiro recai, em âmbito linguístico, na opção por explicar os conceitos contidos nos termos culturalmente marcado. Apresentamos, abaixo, alguns exemplos de explicitação, no que concerne à conceituação contida em termos culturalmente marcados no TM de Rabassa:

(TO) Por tudo isso é que os mamelucos paulistas se tornaram como mateiros e sertanistas ainda melhores que os próprios índios - o terror dos grupos tribais livres e dos índios catequisados pelos jesuítas, nesse processo desestimulados para a luta, e, mais tarde, dos negros fugidos e concentrados em quilombos.

(TT) For all these reasons the São Paulo mamelucos-as men of the jungle and sertão superior even to the Indians themselvesbecame the terror of free tribal groups and Indians catechized by the Jesuits and later of run-away blacks and those gathered in quilombos.

(TO) Da casa-grande, com a figura do senhor, da sinhá, das sinhazinhas e suas mucamas, temos descrições as mais expressivas e nostálgicas de uma antropologia que sempre focalizou o engenho através dos olhos do dono.

(TT) The great house, along with the figures of the master, the mistress, the young mistresses, and their personal slave girls or mucamas, have received lyrical and nostalgic description in an anthropology always viewing the plantation through the eyes of the owner

(TO) Esse descaso para com a educação popular bem como o pouco interesse pelos problemas de bem-estar e de saúde da população explicam-se pelo senhorialismo fazendeiro e pela sucessão tranquila, presidida pela mesma classe dirigente, da Colônia à Independência e do Império à República.

(TT) That disregard for popular education and slight interest in the problems of well-being and health of the population can only be explained by the baronial attitude of the plantation owners and by the peaceful transition, presided over by that same ruling class, from colony to independence and from empire to republic. 
SERPA e CARDOSO DE CAMARGO, A explicitação na tradução inglesa de termos culturalmente marcados da obra O povo brasileiro: a formação e o sentido do Brasil de Darcy Ribeiro.

(TO) Só foi rompida e refundida através do esforço continuado de séculos, anulando qualquer veleidade étnica ou qualquer direito de autodeterminação dos povos avassalados.

(TT) It was broken and reconstituted only through the continuous effort over the centuries that wiped out any ethnic inconstancy or any right of self-determination of the people held in vassalage.

Observamos que, assim como Rabassa utiliza-se de traços de explicitação, principalmente em trechos da obra em que a terminologia antropológica, brasileirismos são aplicados por Darcy Ribeiro no TO. O tradutor apresenta a tendência em explicitar termos simples principalmente por meio de:

1) preposições que, junto a substantivos, designam posse, finalidade, destino, origem, uso, composição, conteúdo e propósito, como em: "sertanista" $\rightarrow$ man of sertão superior;

2) associação entre sentidos, com o uso da partícula or como elemento que indica semelhança, como: "mucamas" $\rightarrow$ personal slave girls or mucamas 5 .

No que diz respeito às possíveis combinatórias entre os termos formando expressões, observamos que a necessidade de explicitar ocorre com menor frequência, Nesse caso, Rabassa trabalha, na sua maioria, com:

3) orações explicativas reduzidas de particípio, como em : "povos avassalados" $\rightarrow$ people held in vassalage;

4) associação de substantivos e adjetivos distintos dos sentidos do $\mathrm{TF}$, procurando promover a constituição de uma ideologia, como em: "senhorialismo fazendeiro" $\rightarrow$ baronial attitude of the plantation owners.

Sendo assim, o tradutor parece utilizar-se da explicitação para compor conceitualidades distintivas, principalmente por meio de um conjunto vocabular próprio da Língua Meta (LM), o que favorece uma leitura e compreensão distanciada do TF e do TM. Abaixo, apresentamos mais exemplos deste traço tradutório:

\footnotetext{
${ }^{5}$ Tais observações também foram apresentadas no artigo supramencionado.
} 
SERPA e CARDOSO DE CAMARGO, A explicitação na tradução inglesa de termos culturalmente marcados da obra O povo brasileiro: a formação e o sentido do Brasil de Darcy Ribeiro.

\section{COMPADRE}

(TO) O senhor, quando presente, se fazia compadre e padrinho, respeitado por seus homens, mas também respeitador das qualidades funcionais destes, ainda que não de sua dignidade pessoal.

(TO) Para isso se fará compadre, ou foreiro, ou sequaz, ou eleitor (...), de quem the possa assegurar a proteção indispensável.
(TT) The master, when present, would serve as best man and godfather, respected by his men but also respectful of their working skills, if not of their personal dignity

(TT) For that reason he became a compadre or tenant or follower or elector(...) of someone who could assure him the necessary protection.

\section{CLASSE SENHORIAL}

(TO) Desenvolveu-se simultaneamente uma classe senhorial de autoridades reais e eclesiásticas, de ricos comerciantes e mineradores, tanto brasileiros como reinóis, acolitada por um amplo círculo de militares de ofício, burocratas, ouvidores, contadores, fiscais e escrivães.

(TO) Exemplificativo disso é a diferença de critérios de um policial ou de um juiz quando se vê diante de ofensas ou danos feitos a um membro da classe senhorial ou a um popular.
(TT) Simultaneously there developed a lordly class of royal and ecclesiastical authorities, wealthy merchants, and mine owners, both Brazilian and Portuguese, served by a wide circle of professional military men, bureaucrats, magistrates, auditors, tax collectors, and clerks.

(TT) This is exemplified by the different criteria in treatment by a policeman or a judge when he has before him a charge of offenses or damages done to a member of the ruling class as opposed to an offense against one of the people.

É possível compreender que há um conhecimento adquirido e uma dada repetição de valores que são não somente linguísticos, mas também 
SERPA e CARDOSO DE CAMARGO, A explicitação na tradução inglesa de termos culturalmente marcados da obra O povo brasileiro: a formação e o sentido do Brasil de Darcy Ribeiro.

sociais. No caso da prática tradutória, tais padrões podem ser representados pelos traços apontados por Baker (1993, 1995, 1996, 1999), entre os quais escolhemos para análise a explicitação.

Nesse sentido, averiguamos a percepção de Rabassa diante da possibilidade que os TFs darcynianos apresentam para a adequação da terminologia a um novo mundo social onde os tradutores estão inseridos, o que favorece, ainda, a geração de inúmeras novas práticas, por parte de outros tradutores e mesmo de novos cientistas sociais.

Por meio da investigação dos traços de explicitação, por conseguinte, notamos claramente como as escolhas lexicais e sintáticas compõem um tipo de conduta tradutória e como o comportamento do tradutor obedece certas regulações sociais, visto que recorrem aos mesmos traços.

Com base nas análises, também pudemos observar como o conhecimento antropológico contido no léxico pode influenciar na formação e na leitura dos tradutores de maneiras diferentes e conduzir a produções terminológicas variadas. Com isso, o processo tradutório atua efetivamente na constituição de uma nova Antropologia da Civilização em LM, rompendo os limites geográficos das ideias e teorias de Darcy Ribeiro e permitindo aos antropólogos estrangeiros conhecerem os valores sociais da visão dos brasileiros pelos brasileiros.

\section{Considerações Finais}

Ao trabalharmos com a tradução da obra O povo brasileiro, compreendemos que os valores e os conhecimentos culturais apresentados por Darcy Ribeiro são entendidos, por Rabassa, como uma nova posição da conduta antropológica, a qual engloba o estado de ser do brasileiro na concepção dos conceitos e das teorias da área. Em decorrência dessa inserção de novas práticas antropológicas, como a identificação do autor com seu objeto de análise, o povo, o tradutor depara-se com diversos brasileirismos em grande quantidade. Assim, passou a realizar um maior número de empréstimos e também promover a recorrência ao traço da explicitação com o objetivo de expor concepções relacionadas ao contexto Nacional.

Notamos que o tradutor depreende os comportamentos do antropólogo Darcy Ribeiro por meio de suas escolhas no âmbito da linguagem de 
SERPA e CARDOSO DE CAMARGO, A explicitação na tradução inglesa de termos culturalmente marcados da obra O povo brasileiro: a formação e o sentido do Brasil de Darcy Ribeiro.

especialidade, e permitem que as condutas terminológicas variáveis do autor repercutam na formação do TM, o qual, em um ciclo de desenvolvimento constante, irá gerar novas terminologias e variações que irão, por sua vez, agir ativamente na compreensão teórica por parte do público alvo.

Conseguimos, pois, observar como o processo e o produto tradutórios repercutem na constituição da linguagem da Antropologia da Civilização e como a variação nas escolhas do léxico pode também alterar os conceitos e promover novas interpretações tanto para a Cultura Fonte quanto para a Cultura Meta.

\section{Referências}

CORPUS PRINCIPAL (PARALELO) DE ANTROPOLOGIA DA CIVILIZAÇÃO

RIBEIRO, D. O povo brasileiro: a formação e o sentido do Brasil. São Paulo: Companhia das Letras, 1995.

Gregory

. The Brazilian People: formation and meaning of Brazil, Translated by

Rabassa. Gainesville: University Press of Florida, 2000.

ALUÍSIO, S., et. al., The Lacio-Web Project: overview and issues in Brazilian Portuguese corpora creation. In: Corpus Linguistics. Lancaster, Inglaterra, 2003, v. 16, p. 14-21.

BARROS, L. A. Curso básico de Terminologia. São Paulo: EDUSP, 2004.

BAKER, M. In other words: a coursebook on translation. London and New York: Routledge, 1992.

Corpus linguistics and translation studies: implications and applications. In BAKER, M.; FRANCIS, G.; TOGNINI-BONELLI, E. (Org.). Text and technology: in honour of John Sinclair. Amsterdam: John Benjamins. 1993, p. 233-250.

Corpora in translation studies: an overview and some suggestions for future research. Target, Amsterdam, v. 7. n2. 1995, p. 223-243.

. Corpus-based translation studies: the challenges that lie ahead. In: SOMERS, Herald. (Ed). Terminology, LSP and translation studies in language engineering: in honour of Juan C. Sager. Amsterdam: John Benjamins. 1996, p. 177-186.

Linguística e estudos culturais: paradigmas complementares ou antagônicos nos estudos da tradução? In: MARTINS, M. A. P. (Org). Tradução e multidisciplinaridade. Rio de Janeiro: Lucena. 1999, p. 15-34.

Towards a Methodology for investigation the style of literary translation. Target, Amsterdã, V. 12, n. 2. 2000, p.241-266. 
SERPA e CARDOSO DE CAMARGO, A explicitação na tradução inglesa de termos culturalmente marcados da obra O povo brasileiro: a formação e o sentido do Brasil de Darcy Ribeiro.

BERBER SARDINHA, T. Lingüística de Corpus. Barueri, SP: Manole, 2004.

CAMARGO, D. C. de. Padrões de estilo de tradutores: um estudo de semelhanças e diferenças em corpora de traduções literárias, especializadas e juramentadas. 512 f. Tese (Livre-Docência em Tradução) - Instituto de Biociências, Letras e Ciências Exatas - Unesp, Universidade Estadual Paulista, São José do Rio Preto, 2005.

Metodologia de pesquisa em tradução e linguística de corpus. São Paulo: ultura Acadêmica/São José do Rio Preto: Laboratório Editorial. (Coleção Brochuras, v.1) 2007.

COSTA, B.E. Pré-edição de um dicionário de brasileirismos terminológicos. Projeto de Iniciação Científica. CNPQ-UnB, Brasília, 2006.

. Brasileirismos Terminológicos: estados de verbos em ação e processo. 2008, 188f. Dissertação (Mestrado em Linguística) - Programa de PósGraduação em Linguística, Português e Línguas Clássicas da Universidade de Brasília.

FAULSTICH, E. Duas questões em discussão: o que são brasileirismos nos dicionários de Língua Portuguesa? Existem brasileirismo terminológicos? In: Jornada sobre "Variación Geolectal i Terminologia" Red Panlatina de Terminología Realiter/IULAterm/Institut Universitari de Linguística Aplicada. Barcelona, Espanha, 24 de novembro de 2004.

SERPA, T.; CAMARGO, D. C. de. A explicitação como traço de um habitus tradutório para brasileirismos terminológicos em língua inglesa: um estudo baseado no corpus da obra O Povo Brasileiro, de Darcy Ribeiro.PERcursos Linguísticos, p. 61-80, 2013.

TYMOCZKO, M. Computerized Corpora and the Future of Translation Studies. Meta, Montreal, v.43, n.4, p. 652-659, 1998.

WINICK, C. Dictionary of Anthropology. London: Peter Owell, 1961.

Resumo: Este artigo verifica a explicitação na tradução inglesa de termos culturais da obra O povo brasileiro de Darcy Ribeiro. Fundamenta-se nos Estudos da Tradução Baseados em Corpus (BAKER, 1995, 1996; CAMARGO, 2005), na Linguística de Corpus (BERBER SARDINHA, 2000, 2004) e na Terminologia (BARROS, 2004). Para Baker (1996), a explicitação é a tendência de explicar, no texto traduzido, trechos que se apresentam implícitos no texto fonte. Esse traço pode ser encontrado na tradução de termos do teórico brasileiro, evidenciando a necessidade de esclarecer a terminologia que descreve o universo brasileiro. 
SERPA e CARDOSO DE CAMARGO, A explicitação na tradução inglesa de termos culturalmente marcados da obra O povo brasileiro: a formação e o sentido do Brasil de Darcy Ribeiro.

Palavras-Chave: Estudos da Tradução Baseados em Corpus, Linguística de Corpus, Explicitação, Darcy Ribeiro.

Abstract: The main purpose of this article is to investigate explicitation in English translation of cultural terms in the work O povo brasileiro, written by Darcy Ribeiro. Corpus-Based Translation Studies (BAKER, 1995, 1996, 1997; CAMARGO, 2005, 2007), Corpus Linguistics (BERBER SARDINHA, 2004) and Terminology (BARROS, 2004) were used. According to Baker (1996), explicitation is the overall tendency to explain, in the target text, parts of the source text that had been left implicit. This feature may be found in Ribeiro's text, indicating the necessity of explicating terminology that describes this universe.

Keywords: Corpus-Based Translation Studies, Corpus Linguistic, Explicitation, Darcy Ribeiro. 